\title{
Overcoming the Plateau: Reducing Impaired Driving by Addressing Drug-Impaired Drivers
}

\author{
Stephen K Talpins* and Patrice Rogers \\ Institute for Behavior and Health Former Assistant State Attorney with the Miami-Dade County (Florida), \\ Traffic Safety Research, USA
}

Submission: April 14, 2017; Published: April 27, 2017

*Corresponding author: Stephen K Talpins, Institute for Behavior and Health and Former Assistant State Attorney with the Miami-Dade County (Florida), State Attorney's Office, USA, Tel: 305-610-3585; Email: sktalpins@aol.com

\section{Introduction}

The United States continues to suffer from a significant impaired driving problem, in no small part because policymakers and practitioners have focused almost entirely on only one cause of impaired driving: alcohol misuse. During the almost four decades since Candace Lightner founded Mothers Against Drunk Driving (MADD) in 1980, the nation has invested tremendous resources designed to change social norms about drinking and driving and buttressing the identification, apprehension, prosecution, punishment, and rehabilitation of drunk drivers. Consequently, the prevalence of drinking drivers and alcoholimpaired drivers has plunged since the 1970's. During the 2013-2014 National Roadside Survey (NRS), 8.3\% of weekend nighttime drivers tested positive for any amount of alcohol, a huge decline from a similar survey in 1973 (35.9\%) [1-3]. Further, the NRS found that only $1.5 \%$ of drivers tested with blood or breath alcohol concentrations (BAC) above the current 0.08 illegal limit, also a big drop from 1973 (7.5\%). See A. Berning, R. Compton, and K. Wochinger, Results of the 2013-2014 National Roadside Survey of Alcohol and Drug Use by Drivers, Traffic Safety Facts (NHTSA February 2015) [1]. Correspondingly, alcoholrelated and alcohol-impaired fatalities dropped significantly as well. In 2014, an estimated $36 \%$ of fatal crashes involved at least one driver with a BAC of 0.01 or higher $(31 \%$ of the drivers had a BAC of 0.08 or higher), a dramatic change from the mid1970 's when "over $60 \%$ of traffic fatalities" were alcohol-related. See e.g. Alcohol-Impaired Driving, Traffic Safety Facts: 2014 Data (NHTSA December 2015) [2] and Fact Sheet: Alcohol-Related Traffic Deaths (National Institutes of Health October 2010) [3]. However, the nation's progress has stalled during the past 10 years. See e.g. Alcohol-Impaired Driving, Traffic Safety Facts: 2014 Data (NHTSA December 2015) [4].

While the nation has focused on and has effected reductions in the number of alcohol-impaired drivers, ithas all but ignored drugged drivers, particularly those who drove with blood alcohol levels above the illegal limit. Not surprisingly, the number of people driving with drugs in their systems has increased dramatically. During the 2013-2014 NHTSA survey, $22.5 \%$ of weekend nighttime drivers tested positive for drugs, a significant increase from 2007 when NRS researchers first began testing drivers for drugs they found that $16.3 \%$ of weekend nighttime drivers tested positive. See Compton, R. and Berning, A., Results of the 2007 National Roadside Survey of Alcohol and Drug Use by Drivers (NHTSA July 2009) [5] and A Berning et al, supra. In that interim the portion of traffic fatalities attributable to drugged drivers also increased. In a 1988 Report to Congress, NHTSA estimated that $10 \%$ to $15 \%$ of killed drivers had drugs in their systems at the time of their crash. See e.g. Terhune, K., et al, The Incidence and Role of Drugs in Fatally Injured Drivers (NHTSA October 1992) [6].

During a 14 month period in 1990 and 1991, 17.8\% of killed drivers from seven states tested positive for drugs at the time of their crash. See e.g. id. Nationwide, between 2005 and 2013, the percentage of drivers involved in fatal crashes with known test results who tested positive for drugs increased from $28 \%$ to almost 40\% (39.9\%). See Drug Involvement of Fatally Injured Drivers, Traffic Safety Facts (NHTSA November 2010) [7], Berning, A. and Smither, D., Understanding the Limitations of Drug Test Information, Reporting, and Testing Practices in Fatal Crashes, Traffic Safety Facts (NHTSA November 2014) [8], and Hedlund, J., Drug-Impaired Driving: A Guide for What States Can Do (Governors Highway Safety Association and Foundation for Advancing Alcohol Responsibility 2016) [9].

States that have legalized marijuana for medicinal use and/or recreational use generally have seen appreciable increases in drug-crash-involvement following passage of their new laws. In Colorado, after laws passed making marijuana commercially available for both medicinal use and recreational use, researchers found a twofold increase in the proportion of drivers in fatal motor vehicle crashes who tested positive for marijuana (change in trend, 2.16 (0.45), $\mathrm{p}<0.0001$ ); in contrast, they saw no significant increases in non-legalized-marijuana 


\section{Global Journal of Addiction \& Rehabilitation Medicine}

states and no significant changes in the proportion of drivers in a fatal motor vehicle crash who were alcohol-impaired. See Salomonsen-Sautel, S., et al, Trends in fatal motor vehicle crashes before and after marijuana commercialization in Colorado, 140 Drug and Alcohol Dependence 137 (2014) [10]. See also Wong, K., Clarke, C., and Harlow, T., The Legalization of Marijuana in Colorado - The Impact, Volume 4 (Rocky Mountain High Intensity Drug Trafficking Area September 2016) [11].

In Washington, marijuana-involved fatal crashes doubled following passage of their recreational use law. In Washington, the percentage of drivers in fatal crashes testing above the illegal limit for alcohol and no drugs fell by more than $25 \%$ from 2013 to 2014, the year following commercialization of legal marijuana. Drug Toxicology Testing and the Involvement of Marijuana in Fatal Crashes, 2010-2014 (Washington Traffic Safety Commission 2016) [12]. During the same time period, the percentage of drivers that tested positive for THC alone increased by over $185 \%$ and the percentage that tested both over the illegal BAC limit and positive for THC increased more than $37 \%$. Id. In California, for the first time since collecting this data in the mid-1990s, since 2012 there have consistently been more crash fatalities involving drugs either alone or in combination with alcohol than involving alcohol alone. See e.g. Brown Jr, E and Shiomoto, J. Annual Report of the California DUI Management Information System (California Department of Motor Vehicles 2015) [13].

Of course, many drivers use both alcohol and drugs. We believe that this systematic failure to address drugged driving has contributed not only to an exacerbation of the nation's drugged driving problem, but also to the nation's inability to further reduce the number of people killed in crashes including those caused by alcohol-impaired drivers. In this article, we discuss the nation's failure to identify drugged drivers, its impact on DUI recidivism, and a strategy for addressing the issues.

\section{Standard Operating Procedures for Testing Suspected DUI Drivers for Alcohol and Drugs}

Officers in the United States administer the Standardized Field Sobriety Tests (SFST) to all drivers they suspect of driving under the influence of alcohol and/or drugs (DUI) at roadside. These tests are non-specific; in other words, they enable officers to identify impaired drivers but do not allow them to determine whether the source of the subject's impairment is alcohol or drugs. See e.g. Steuer, A., Eisenbeiss, L., Kraemer, T., Blood alcohol analysis alone versus comprehensive toxicological analysis - Systematic investigation of missed co-ingested other drugs in suspected alcohol-impaired drivers, 267 Forensic Science International 52 (2016) [14] and Talpins, S. and Hayes, C., The
Drug Evaluation and Classification (DEC) Program at 8 (National District Attorneys Association October 2004) [15].

If the officers conclude that drivers are impaired, they test or attempt to test them for alcohol according to standard operating procedure (SOP). In every state, drivers with blood alcohol levels of 0.08 grams of alcohol per 100 milliliters of blood or its equivalent in breath are "per se" guilty of driving under the influence (DUI). In virtually every jurisdiction, law enforcement officers refrain from testing drivers who provide a blood or breath test level at or above the 0.08 illegal limit for alcohol as a matter of SOP unless someone is seriously injured or is killed. See e.g. Voas, R., DuPont, R., Shea, C., and Talpins, S, Prescription drugs, drugged driving and per se laws, 19 Injury Prevention 218 (2013) [16]. This makes DUI the only known crime where officers terminate their examinations before collecting all of the evidence and completing their investigations as a matter of SOP.

Current SOP's prevent the identification of drivers who use drugs because the vast majority of impaired driving arrestees test above the illegal. 08 BAC limit. For example, in 1994, the Miami-Dade County State Attorney's office reviewed data from 25,129 cases from 1991-1993. They found approximately $88 \%$ of those arrested for misdemeanor DUI tested at or above the 0.08 illegal limit and $91 \%$ tested above the limit or refused to provide breath samples for testing. Talpins, S. and Hayes, C. supra. The refusal data is meaningful because the state suspends the driver's licenses of DUI arrestees who refuse to provide breath samples upon proper request. See F.S. § 322.2615 a similar analysis of data from Nebraska collected between 2002 and 2004 yielded almost identical results: over $81 \%$ of arrestees tested at or above the illegal limit and almost $90 \%$ test above the limit or refused to provide breath samples for testing. See County's Response to the Defendant's Motion to Determine the Admissibility of Drug Recognition Evidence in State v. Schnell, CR-4-494 (Hall County 2005) [17].

As with Florida, the refusal data is meaningful because Nebraska suspends the driver's licenses of DUI arrestees who refuse to provide a breath sample upon proper request. See R.R.S. Neb. § 60-498.01. Law enforcement agencies did not create the drug testing SOPs arbitrarily. The SOPs were born out of the nation's laser-like focus on alcohol-impaired drivers and the challenges associated with traditional drug testing methods. However, the SOPs survive for two primary reasons. First, most state laws do not provide for additional charges or enhanced penalties if a person drives under the influence of both alcohol and drugs $\left({ }^{1}\right)$. Second, most agencies are unaware of the implications for not testing alcohol-impaired drivers for drugs. See below for a discussion on this issue.

An expert panel convened by the Governors Highway Safety Association (GHSA) and Foundation for Advancing Alcohol Responsibility (FAAR) recommended multiple measures for improving drugged driving enforcement and prosecution, including the passage of separate laws and penalties for people who drive under the influence of drugs or a combination of alcohol and drugs. In addition to discouraging drugged driving and polysubstance involved driving, it would facilitate the tracking of drugged driving charges. See e.g. Hedlund, J., Drug Impaired Driving: A Guide for What States Can Do (GHSA and FAAR 2016). 


\section{Global Journal of Addiction \& Rehabilitation Medicine}

Third, most law enforcement officers are unfamiliar with the lower cost and ease of modern drug testing methods. Historically, officers had no simple means to test DUI arrestees for drugs in the field. Officers who wanted to test DUI suspects for drugs collected urine and/or blood samples for laboratory submission. Urine and blood testing are time consuming and expensive. Agencies relied on these inefficiencies and costs to justify the conservative drug testing SOPs. During the past decade, however, various private companies developed reasonably sensitive and reliable oral fluid screening kits. These kits now enable officers to quickly, inexpensively, and reliably screen arrestees for drugs and determine those who should submit to further laboratory testing. See e.g. Flannigan, J., Moore, C., and Talpins, S, Oral Fluid Testing for Impaired Driving Enforcement, The Police Chief 58 (January 2017) [18]; Hedlund, J., supra, Talpins, S., Dupont, R., Walls, C., et al. The Miami Dade Protocol: Making Drugged Driving Enforcement a Reality, 3 Alcoholism \& Drug Dependence 212 (2015) [19]. See also Kimball, T. The Next Big Thing: Oral Fluid Testing for Drug Impairment, 44 DUI News 1 (Tennessee District Attorneys General Conference September 2013) [20] and Renick, P. and Flintoft, J., Oral Fluid Evidence in Drugged Driving Cases, 44 DUI News 8 (Tennessee District Attorneys General Conference September 2013) [21]. Unfortunately, while policy makers and law enforcement agencies are starting to use onsite oral fluid testing, they have been slow to take advantage of technology by adapting their SOPs and testing all impaired drivers for drugs. Id. A recent court decision, may, however, speed the process. In State v. Salas, Case No. BF153631A (Cal. Kern Co., November 30,2015 , oral order), a California trial judge ruled that onsite drug test results were admissible under the state's version of the Frye standard (the Kelley-Frye standard). Proponents of these kits believe Salas will encourage other jurisdictions to test more drivers even though the opinion is not binding on any other courts. See e.g. Douglas, T., "Kern's use of oral swab in DUI case watched nationwide," Bakersfield.com (January 10, 2016) [22] (retrieved on March 11, 2017 at Retrieved from http://www. bakersfield.com/news/kern-s-use-of-oral-swab-in-dui-casewatched/article_54766e6e-d5bb-5333-b7c8-42079404cb07. html).

\section{Alcohol and Drug Use Among DUI Offenders}

The vast majority of DUI offenders abuse alcohol. However, a sizable portion also abuse drugs, either alone or in combination with alcohol as reflected by crash data and studies of offenders. See e.g. Brown Jr, E and Shiomoto, J. Annual Report of the California DUI Management Information System (California Department of Motor Vehicles 2015) [23] and the below referenced research. In a study involving 729 residents of a DUI residential program in Massachusetts, researchers found that the lifetime psychiatric disorder prevalence rates for alcohol abuse or dependence in men and women were $98.1 \%$ and $95.5 \%$, respectively; for drugs the rates were $42.3 \%$ and $33 \%$, respectively. See e.g. LaPlante, D., et al, Substance and Psychiatric Disorders Among Men and Women Repeat Driving Under the Influence Offenders Who Accept a Treatment-Sentencing Option, Journal of Studies on Alcohol and Drugs 209 (March 2008) [24].

In a study of 46,689 offenders admitted to substance abuse treatment programs with one or more past year DUI arrests in Texas, researchers found thirty-four percent (34\%) of those with one DUI arrest in the past year and $26 \%$ of those with two or more past year arrests had a primary problem with drugs. See Maxwell, J., Drunk versus drugged: How different are the drivers?, 121 Drug and Alcohol Dependence 68 (2012) [25]. Thirty-five percent $(35 \%)$ of people with one DUI arrest in the past year whose primary problem was alcohol also "had problems" with drugs. Id. Research suggests that the majority of repeat DUI offenders suffer from drug abuse or dependence. See e.g. Lapham, S., C' de Baca, J., McMillan, G., and Lapidus, J., Psychiatric Disorders in a Sample of Repeat Impaired-Driving Offenders, 67 Journal of Studies on Alcohol and Drugs 707 (2006) [26]. While most drivers with BACs of 0.08 or higher have no drugs in their system at the time of their arrest, a substantial portion of them do. In a review of drivers arrested for DUI between 1992 and 1994 in 46 California counties, researchers found that $60 \%$ of drivers with BACs of equal to or less than 0.08 were positive for drugs, well before liberalized marijuana laws. See e.g. Marowitz, L., Predicting DUI Recidivism: Blood Alcohol Concentration and Driver Record Factors, 30 Accident Analysis and Prevention 545 (1998) [27]. The study found decreasing drug involvement as BAC levels increased and drugs were present at all BAC levels screened. Id. In a follow-up review of 53,217 subjects arrested between January 1, 1993 and June 30,1993 in the same counties, researchers found that $40 \%$ of those with BAC's of 0.08 tested positive for drugs. Id. The prevalence of drugs was not examined in either study for drivers arrested with BAC levels higher than 0.08 since most of the drivers were not tested for drugs in accordance with standard operating procedures. Id. Regardless, the results are impressive, particularly since the laboratories could only test for six types of drugs. Id. In a small MiamiDade County Florida study, 39\% of DUI arrestees with BACs at or above the illegal limit tested positive for at least one drug category. See e.g. Logan, B., Mohr, A., and Talpins, S., Detection and Prevalence of Drug Use in Arrested Drivers Using the Drager Drug Test 5000 and AffinitonDrugWipe Oral Fluid Drug Screening Devices, Journal of Analytical Toxicology 1-7 (doi:10 10.1093/ jat/bku050) (2014) [28]. California and Miami's experiences are not unique. In a sample of 500 cases from Zurich, Switzerland, researchers found that $37 \%$ of the drivers initially suspected of being impaired by alcohol alone also had drugs in their system. See Steuer, A., Eisenbeiss, L., Kraemer, T., Blood alcohol analysis alone versus comprehensive toxicological analysis - Systematic investigation of missed co-ingested other drugs in suspected alcohol-impaired drivers, 267 Forensic Science International 52 (2016) [29].

What's more, the more recalcitrant the offender, the more likely they are to abuse multiple substances. There is a direct relationship between the number of DUI convictions and drug 


\section{Global Journal of Addiction \& Rehabilitation Medicine}

use: the more convictions a person has, the more likely they are to abuse drugs. See e.g. McCutcheon, V., et al, Alcohol criteria endorsement and psychiatric and drug use disorders among DUI offenders: Greater severity among women and multiple offenders, 34 Addictive Behaviors 432 (2009) [30].

\section{DUI Offender Screening, Assessment, and Treatment}

The failure to test DUI arrestees with BACs above 0.08 for drugs has significant consequences. In every state, people who are convicted of DUI are evaluated for substance misuse issues. Probation officers and treaters use these evaluations, which typically (and necessarily) are based upon self-reports, to determine the nature and extent of treatment DUI offenders receive. In other words, they only address offenders' known substance misuse issues. However, offenders often underreport their issues and problems, intentionally or otherwise. See e.g. Lapham, S., C'de Baca, Chang, I., Hunt, W., Berger, L., Are drunkdriving offenders referred for screening accurately reporting their drug use?, 66 Drug and Alcohol Dependency 243 (2002) [31]. Practitioners and researchers attribute the underreporting to a variety of causes, including a fear of being forced to undergo treatment. Id $\left({ }^{2}\right)$. In one study of 1,078 first time offenders, researchers found that approximately $28 \%$ of the offenders whom evaluators determined had no drug problems were misdiagnosed despite a rigorous testing protocol. Id. This is particularly concerning since court-required treatment programs are one of the primary paths to recovery for alcoholimpaired DUI offender. See e.g. Atkinson, R., Misra, S., Ryan S., and Turner, J., Referral paths, patient profiles and treatment adherence of older alcoholic men, 25 Journal of Substance Abuse Treatment 29 (2003) [32]. Offenders who lie about their drugmisuse issues can avoid the more extensive monitoring and drugspecific treatment they need absent objective evidence that they have a problem, thus undermining chances of rehabilitation. Stated differently, absent evidence that an individual has a problem with drugs, the criminal justice system cannot serve an offender in this important path to drug-problem recovery.

DUI recidivism is much higher than it should be. Recently, NHTSA reviewed data from a multitude of states and analyzed recidivism rates for DUI offenders. In states with at least a 10 year "look-back period," they determined that a weighted mean of $27 \%$ of offenders were rearrested and $32 \%$ of offenders were re-convicted in a four year period. Warren-Kigenyi, N. and Coleman, H., DWI Recidivism in the United States: An examination of State-Level Driver Data and the Effect of Look-Back Periods on Recidivism Prevalence, Traffic Safety Facts Research Note (NHTSA March 2014) [33]. These figures are particularly concerning since "only a small percentage of impaired drivers are detected and arrested; about one in 200 drivers." Id $\left({ }^{3}\right)$. The failure to identify alcohol-impaired drivers with co-morbid drug abuse issues may account for at least a portion of the reason why DUI recidivism rates are so high.

DUI offenders who use and abuse drugs may have a greater need for intervention than those who abuse alcohol alone. Researchers conducted a study involving 46,689 DUI offenders admitted to treatment programs between 2005 and 2009 found that "DUI offenders with primary problems with drugs other than alcohol or cannabis were more impaired, reported more problems, more daily use, and more mental health disorders" than offenders with predominately alcohol problems. See Maxwell, J., Drunk versus drugged: How different are the drivers?, 121 Drug and Alcohol Dependence 68 (2012) [34]. However, these findings, like any studies limited to offenders under treatment, may be influenced by the very fact that all of these offenders were admitted to treatment.

However, and consistent with the notion that drug offenders may have a greater need for intervention, several studies of all arrested DUI offenders suggest that DUI offenders with drug problems are more likely to recidivate than those with alcohol alone problems. In 1995, researchers examined the relationship between BAC and recidivism for all persons convicted of DUI in California during the first six months of 1993 (53,217 subjects). They found that "the maximum predicted rate of recidivism for both first and repeat offenders is at a BAC of $0.00 \%$." See Marowitz, L., Predicting DUI Recidivism: Blood Alcohol Concentration and Driver Record Factors, 30 Accident Analysis and Prevention 545 (1998) [35]. Obviously, "[a] BAC of $0.00 \%$ found in drivers convicted of DUI is undoubtedly an indication of the presence and influence of drugs other than alcohol."More recently, researchers examined data from 453 repeat offenders participating in a voluntary intensive supervision program in Portland, Oregon. Each of the offenders had an alcohol-use disorder. Fifty-four percent (54\%) of the offenders also had a drug-use disorder. Overall, those with a co-occurring druguse disorder were no more likely to be involved in a motor vehicle crash than those with alcohol-use disorders alone, but had a $13 \%$ greater unadjusted relative risk of being convicted for a traffic offense. More specifically, offenders with a central nervous system (CNS) depressant-use disorder were 36\% more likely to be involved in a motor vehicle crash. Offenders with a CNS stimulant-use disorder were no more likely to be involved in a crash, but had a $28 \%$ greater likelihood for lifetime traffic violations. See C'de Baca, J., McMillan, G.P., and Lapham, S.C., Repeat DUI Offenders Who Have Had a Drug Diagnosis: Are They More Prone to Traffic Crashes and Violations?, 10 Traffic Injury Prevention 134 (2009) [36].

The underreporting is not confined to drug use. Researchers found that the same population underreported alcohol abuse and dependence by $59 \%$. See e.g. Lapham, S., C' de Baca, J., McMillan, G., Hunt, W., Accuracy of alcohol diagnosis among DWI offenders referred for screening, 76 Drug and Alcohol Dependence 135 (2004).

Some research suggests this figure may be overly optimistic. See e.g. White, W. and Gasperin, D., The "Hard Core Drinking Driver," 25 Alcoholism Treatment Quarterly 113 (2007). 


\section{Global Journal of Addiction \& Rehabilitation Medicine}

Researchers in Norway examined records from 1,102 drug impaired drivers and 850 alcohol impaired drivers whose BACs were between 0.16 and 0.19 (ie, approximately twice the illegal limit) at the time of their arrests in $1992\left({ }^{4}\right)$. When they analyzed the records retrospectively and prospectively from 1984 to 1998 , they learned that $71 \%$ of the drug-impaired drivers and $40 \%$ of the alcohol impaired drivers were arrested two or more times. When they analyzed the records prospectively for seven years, they found the re-arrest rates for drugged drivers were approximately double the rates for alcohol-impaired drivers (57\% versus 28\%). See Christopherson, A.S., Skurtveit, S., Grung, M., and Morland, J., Rearrest rates among Norwegian drugged drivers compared with drunken drivers, 66 Drug and Alcohol Dependence 85 (2002) [37].

Researchers in Sweden and Finland had similar findings. In Sweden, researchers examined data from 36,799 drivers arrested for DUI between 2001 and 2004 had similar findings. They determined that the re-arrest rate for alcohol-impaired drivers was $14 \%$, while the re-arrest rate for prescription drug impaired drivers was $17 \%$ and for illicit drug impaired drivers it was $68 \%$ over four years. See Holmgren, A., Holmgren, P., Kugelberg, F., Jones, A.W., and Ahlner, J., High re-arrest rates among drug-impaired drivers despite zero-tolerance legislation, 40 Accident Analysis and Prevention 534 (2008) [38]. In Finland, researchers found that among 194,932 total drivers arrested for DUI there between 1993 and 2007alcohol-impaired drivers had a re-arrest rate of $31 \%$. Drivers impaired by drugs or both alcohol and drugs both had significantly higher rates: $44 \%$ and $43 \%$, respectively). Relevantly, drivers who tested positive for cannabinoids were more (1.61 times) likely to be re-arrested as those who tested positive for alcohol alone. See Impinen A, Rahkonen O, Karjalainen K, Lintonen T, Lilsunde P, et al. Substance Use as a Predicator of Driving under the Influence (DUI) Rearrests. A 15-Year Retrospective Study, 10 Traffic Injury Prevention 220 (2009) [39].

\section{Conclusion}

The data strongly suggest that practitioners can significantly reduce impaired driving by identifying offenders with drugabuse issues. Of course, they cannot address a problem they don't know about. We strongly recommend that states determine the prevalence of drugged driving and test all DUI arrestees for drugs so that law enforcement agencies, courts, probation officers, and treatment providers can appropriately direct resources to address the problem and help those most in need of intervention. Following this recommendation will have the added benefit of providing the data necessary to conduct more refined studies of recidivism and crash involvement among both alcohol- and drug-involved DUI offenders and allow for more appropriately targeted interventions.

\section{References}

1. A Berning, R Compton, K Wochinger (2015) Results of the 2013-2014 National Roadside Survey of Alcohol and Drug Use by Drivers, Traffic Safety Facts.

2. (2015) Alcohol-Impaired Driving, Traffic Safety Facts: 2014 Data.

3. (2010) Fact Sheet: Alcohol-Related Traffic Deaths (National Institutes of Health).

4. (2015) Alcohol-Impaired Driving, Traffic Safety Facts: 2014 Data (NHTSA).

5. Compton R, Berning A (2009) Results of the 2007 National Roadside Survey of Alcohol and Drug Use by Drivers. NHTSA.

6. Terhune K (1992) The Incidence and Role of Drugs in Fatally Injured Drivers. NHTSA.

7. (2010) Drug Involvement of Fatally Injured Drivers, Traffic Safety Facts. NHTSA.

8. Berning A, Smither D (2014) Understanding the Limitations of Drug Test Information, Reporting, and Testing Practices in Fatal Crashes. Traffic Safety Facts. NHTSA.

9. Hedlund J (2016) Drug-Impaired Driving: A Guide for What States Can Do (Governors Highway Safety Association and Foundation for Advancing Alcohol Responsibility).

10. Salomonsen-Sautel S (2014) Trends in fatal motor vehicle crashes before and after marijuana commercialization in Colorado. Drug and Alcohol Dependence 140: 137.

11. Wong K, Clarke C, Harlow T (2014) The Legalization of Marijuana in Colorado - The Impact, Volume 4, Rocky Mountain High Intensity Drug Trafficking.

12. (2016) Drug Toxicology Testing and the Involvement of Marijuana in Fatal Crashes, 2010-2014 (Washington Traffic Safety Commission 2016)

13. Brown JR, Shiomoto J (2015) Annual Report of the California DUI Management Information System (California Department of Motor Vehicles 2015).

14. Steuer A, Eisenbeiss L, Kraemer, T (2016) Blood alcohol analysis alone versus comprehensive toxicological analysis - Systematic investigation of missed co-ingested other drugs in suspected alcohol-impaired drivers. Forensic Science International 267: 52.

15. Talpins S, Hayes C (2004) The Drug Evaluation and Classification (DEC) Program at 8 (National District Attorneys Association).

16. Voas R, DuPont R, Shea C, Talpins S (2013) Prescription drugs, drugged driving and per se laws. Injury Prevention 19: 218.

17. (2005) County's Response to the Defendant's Motion to Determine the Admissibility of Drug Recognition Evidence in State v. Schnell, CR-4494.

18. Flannigan J, Moore C, Talpins S (2017) Oral Fluid Testing for Impaired Driving Enforcement. The Police Chief 58.

19. Hedlund J, supra, Talpins S, Dupont R, Walls C, et al. (2015) The Miami Dade Protocol: Making Drugged Driving Enforcement a Reality. Alcoholism \& Drug Dependence 3: 212.

Among killed drivers with alcohol in their systems, the "most frequently recorded BACs" were "tied at .14 and .16" in 2014. Alcohol-Impaired Driving, Traffic Safety Facts: 2014 Data (NHTSA December 2015). 
20. Kimball T (2013) The Next Big Thing: Oral Fluid Testing for Drug Impairment, 44 DUI News 1 (Tennessee District Attorneys General Conference).

21. Renick P, Flintoft J (2013) Oral Fluid Evidence in Drugged Driving Cases, 44 DUI News 8 (Tennessee District Attorneys General Conference).

22. Douglas T (2016) Kern's use of oral swab in DUI case watched nationwide. Bakersfield.com.

23. Brown E, Shiomoto J (2015) Annual Report of the California DUI Management Information System (California Department of Motor Vehicles 2015).

24. LaPlante D (2008) Substance and Psychiatric Disorders Among Men and Women Repeat Driving Under the Influence Offenders Who Accept a Treatment-Sentencing Option. Journal of Studies on Alcohol and Drugs 69(2): 209-217.

25. Maxwell J (2012) Drunk versus drugged: How different are the drivers? Drug and Alcohol Dependence 121(1-2): 68-72.

26. Lapham S, C' de Baca J, McMillan G, Lapidus J (2006) Psychiatric Disorders in a Sample of Repeat Impaired-Driving Offenders. Journal of Studies on Alcohol and Drugs 67: 707-713.

27. Marowitz L (1998) Predicting DUI Recidivism: Blood Alcohol Concentration and Driver Record Factors. Accident Analysis and Prevention 30(4): 545-554

28. Logan B, Mohr A, Talpins S (2014) Detection and Prevalence of Drug Use in Arrested Drivers Using the Drager Drug Test 5000 and Affiniton Drug Wipe Oral Fluid Drug Screening Devices. Journal of Analytica Toxicology 1-7.

29. Steuer A, Eisenbeiss L, Kraemer T (2016) Blood alcohol analysis alone versus comprehensive toxicological analysis - Systematic investigation of missed co-ingested other drugs in suspected alcohol-impaired drivers. Forensic Science International 267: 52-59.
30. McCutcheon V (2009) Alcohol criteria endorsement and psychiatric and drug use disorders among DUI offenders: Greater severity among women and multiple offenders. Addictive Behaviors 34: 432.

31. Lapham S, C'de Baca, Chang I, Hunt W, Berger L (2002) Are drunkdriving offenders referred for screening accurately reporting their drug use? Drug and Alcohol Dependency 66: 243.

32. Atkinson R, Misra S, Ryan S, Turner J (2003) Referral paths, patient profiles and treatment adherence of older alcoholic men. Journal of Substance Abuse Treatment 25: 29-35.

33. Warren-Kigenyi N, Coleman H (2014) DWI Recidivism in the United States: An examination of State-Level Driver Data and the Effect of Look-Back Periods on Recidivism Prevalence. Traffic Safety Facts Research Note.

34. Maxwell (2012) Drunk versus drugged: How different are the drivers? Drug and Alcohol Dependence 121(1-2): 68-72.

35. Marowitz L (1998) Predicting DUI Recidivism: Blood Alcohol Concentration and Driver Record Factors. Accident Analysis and Prevention 30: 545 .

36. C'de Baca J, McMillan GP, Lapham SC (2009) Repeat DUI Offenders Who Have Had a Drug Diagnosis: Are They More Prone to Traffic Crashes and Violations? Traffic Injury Prevention 10: 134-140.

37. Christopherson AS, Skurtveit S, Grung M, Morland J (2002) Rearrest rates among Norwegian drugged drivers compared with drunken drivers. Drug and Alcohol Dependence 66: 85-92.

38. Holmgren A, Holmgren P, Kugelberg F, Jones AW, Ahlner J (2008) High re-arrest rates among drug-impaired drivers despite zero-tolerance legislation, 40 Accident Analysis and Prevention 40(2): 534-540.

39. Impinen A, Rahkonen $\mathrm{O}$, Karjalainen K, Lintonen T, Lilsunde P, et al. (2009) Substance Use as a Predicator of Driving under the Influence (DUI) Rearrests. A 15-Year Retrospective Study. Traffic Injury Prevention 10(3): 220-226.

\section{Your next submission with Juniper Publishers} will reach you the below assets

- Quality Editorial service

- Swift Peer Review

- Reprints availability

- E-prints Service

- Manuscript Podcast for convenient understanding

- Global attainment for your research

- Manuscript accessibility in different formats ( Pdf, E-pub, Full Text, Audio)

- Unceasing customer service

Track the below URL for one-step submission https://juniperpublishers.com/online-submission.php 